\section{Reversible sensorimotor impairment following prolonged ventilation with isoflurane and vecuronium for acute severe asthma}

H du Peloux Menagé, S Duffy, D W Yates, $\mathrm{J}$ A Hughes

\begin{abstract}
A patient with acute asthma developed severe sensorimotor neuropathy while being ventilated with isoflurane and receiving vecuronium and fentanyl. The neuropathy resolved spontaneously within three months of the episode. This unusual complication may result from prolonged use of inhalational anaesthesia or of vecuronium, or both.
\end{abstract}

(Thorax 1992;47:1078-1079)

Experience with long term use of inhalational anaesthesia in acute severe asthma is limited. The longest reported use is 18 days with halothane and enflurane and this was associated with transient neuromuscular impairment. ${ }^{1}$ We report a similar case that followed the use of isoflurane given for eight days.

\section{Case report}

A 40 year old woman, who had suffered from asthma since the age of 22 , was admitted with a premenstrual exacerbation and rapid deterioration over 24 hours. She had had four admissions in the preceding 18 months, all associated with premenstrual asthma. Her most recent admission had been two months previously, when she required ventilation for 72 hours, receiving intravenous phenoperidine and midazolam. She smoked 10 cigarettes a day and was taking oral aminophylline $450 \mathrm{mg}$ twice daily, inhaled budenoside $1600 \mu \mathrm{g}$ daily, and inhaled salbutamol as required. Between attacks she was well.

On arrival in casualty she was extremely unwell, with an arterial pH of 6.98, oxygen tension $\left(\mathrm{PaO}_{2}\right)$ of $4.7 \mathrm{kPa}$, and carbon dioxide tension $\left(\mathrm{PaCO}_{2}\right)$ of $14.2 \mathrm{kPa}$. She received an intravenous bolus dose of hydrocortisone and salbutamol $500 \mu \mathrm{g}$ and was paralysed and ventilated. Sedation was maintained with midazolam $5 \mathrm{mg} / \mathrm{h}$ and paralysis with pancuronium $2 \mathrm{mg} / \mathrm{h}$, and she received intravenous salbutamol $5 \mu \mathrm{g} / \mathrm{min}$ and aminophylline $0.014 \mu \mathrm{g} /$ $\mathrm{kg} / \mathrm{min}$. Inflation pressures remained high at $60 \mathrm{~cm} \mathrm{H}_{2} \mathrm{O}$, and on the following day isoflurane in oxygen was introduced via an anaesthetic circle circuit at an estimated concentration of
$1.5 \%$ with a range of $0 \cdot 5-3 \%$. Peak inflation pressures fell within one hour to $40 \mathrm{~cm} \mathrm{H}_{2} \mathrm{O}$. She also received fentanyl $100 \mu \mathrm{g} / \mathrm{h}$ and vecuronium 4-6 mg/h. Bronchial lavage was performed on days 2 and 4 with normal saline. Regular nebulised turbutaline and ipatropium bromide were given, together with parenteral hydrocortisone, aminophylline, and salbutamol, and a one week course of cefuroxime and of enteral feeding. Potassium and phosphate concentrations were maintained within the normal range. Isoflurane and vecuronium were withdrawn on day 9 and ventilation was maintained with phenoperidine and bolus doses of midazolam for sedation. Weaning was difficult and on day 15 a flaccid paresis affecting all four limbs, MRC grade 2, became apparent. Biceps and supinator reflexes were absent and triceps, ankle, and knee jerks depressed. Plantars were flexor and cranials intact. She had no pinprick or cotton wool sensation distally in any of her limbs and a diminished sense of joint position and vibration.

Investigations at this stage showed normal cerebrospinal fluid (protein and glucose concentrations, cell count, oligoclonal bands, and cytology); cervical spine radiographs; creatine kinase activity; and vitamin B12, folate, and blood glucose concentrations. Urinary porphyrins and serum antibodies to the acetylcholine receptor were not detected. Fluoride concentrations were not measured but serum creatinine remained normal, as did the ful blood count and the electrolyte concentrations. Nerve conduction studies were performed at six weeks and showed normal motor and sensory velocity. The median (11 $\mu$ volts) and ulnar (8 $\mu$ volts) sensory action potential amplitudes were marginally small but the sural nerve action potential (18 $\mu$ volts) was normal. Electromyography of the right tibialis anterior showed increased insertional activity, a reduced interference pattern, and short duration polyphasic potentials; but the changes were minimal.

Progress Tracheostomy was performed on day 17 and she was ventilated for a total of 21 days, with a stay of 24 days in the intensive care unit. She received a total dose of hydrocortisone of $6.5 \mathrm{~g}$ over 20 days. Normal lung function had returned by the time of discharge after 51 days in hospital. The addition of progesterone has prevented any further acute attacks.

Neurological management was supportive. An improvement was noted by day 17 and by day 24 the sensory loss had virtually resolved. Motor improvement was slower but at six weeks she was walking and at three months recovery was almost complete. All reflexes returned in the recovery phase. Electrophysiological studies at nine months showed no abnormality.

\section{Discussion}

Isoflurane is a volatile inhalational anaesthetic with actions similar to those of halothane. 
Vecuronium is a competitive neuromuscular blocker, the effects of which may be enhanced by inhalational anaesthetics. Fentanyl and phenoperidine are opioid analgesics. Neuropathy is not a generally recognised complication of these drugs.

Inhalational anaesthetics with bronchodilator properties may be useful in resistant acute severe asthma, ${ }^{23}$ and isoflurane and enflurane are recommended as first line agents in preference to halothane. ${ }^{2}$ Prolonged anaesthesia raises the possibility of toxicity. A reversible flaccid paralysis with glove and stocking sensory loss has been noted in a patient with asthma after ventilation for 14 days with halothane $0 \cdot 5-1 \%$, followed by enflurane $1-$ $2 \%$, in conjunction with vecuronium $0.5 \mathrm{mg} /$ $\mathrm{h} ;{ }^{1}$ the neurological deficits were associated with a rise in creatine kinase activity, myopathic changes in a muscle biopsy specimen, and neurogenic changes detected by electrophysiological studies.

The clinical picture in our patient suggested neuropathy but electrophysiological studies gave inconclusive results: the reduced sensory potentials in the fingers and interference pattern shown by electromyography suggested an axonal process but, in view of the short polyphasic potentials, a coexisting myopathic process could not be excluded. Hydrocortisone myopathy may present with failure to become weaned from ventilation and has been noted with a total dose of hydrocortisone of greater than $5 \mathrm{~g}$, but associated sensory changes have not been a feature. ${ }^{4}$
Acute severe axonal neuropathy has been described in critically ill patients, with flaccid tetraparesis, hyporeflexia, and associated distal sensory loss. ${ }^{5}$ Patients are more ill than our patient, however, often with multiple organ failure or severe sepsis. ${ }^{5}$ Non-depolarising muscle relaxants have been used for years for long term ventilation. They act on the motor end plate rather than directly on nerves. Pancuronium used for more than six days may produce muscle atrophy and axonal degeneration secondary to neuromuscular blockade, but sensory change has not been reported. ${ }^{6}$ It seems increasingly likely therefore that volatile anaesthetic agents can cause neuromuscular impairment.

We are grateful for the help of $\mathrm{Dr} T$ Fowler and $\mathrm{Dr} T$ Panayiotopoulos for reporting on the nerve conduction studies.

1 Tanigaki T, Kondo T, Ohta Y, Yamabayashi H. Transient neuromuscular impairment resulting from prolonged inhalation of halothane and enflurane. Chest 1990;98: 1012-3.

2 Parnass SM, Feld JM, Chamberlin WH, Segil LJ. Status asthmaticus treated with isoflurane and enflurane. Anesth Analg 1987;66:193-5.

3 Revell S, Greenhalgh D, Absalom SR, Soni N. Isoflurane in the treatment of asthma. Anaesthesia 1988;43:477-9.

4 Shee CD. Risk factors for hydrocortisone myopathy in acute severe asthma. Respir Med 1990;84:229-33.

5 Zochodne DW, Bolton CF, Wells GA, Gilbert JJ, Hahn AF Brown JD et al. Critical illness polyneuropathy. A complication of sepsis and multiple organ failure. Brain plication of sepsis

6 Op de Coul AAW, Lambregts PCLA, Koeman J, van Puyenbroek MJE, Ter Laak HJ, Gabreels-Festen AAWM. Neuromuscular complications in patients given Pavulon (pancuronium bromide) during artificial ventilation. Clin Neurol Neurosurg 1985;87:17-22. 